\title{
Awareness and Knowledge of Diabetic Retinopathy (DR) among Al-Batinah Population, Oman-A Pilot Study, 2018
}

\author{
Article by Gopi Suresh Vankudre ${ }^{1}$, Galal Ismail ${ }^{2}$, Shaikha Salim Al-Shumosi ${ }^{3}$ \\ ${ }^{1}$ Master of Optometry, College of Health Sciences, University of Buraimi \\ ${ }^{2}$ Ph. D, College of Health Sciences, University of Buraimi \\ ${ }^{3}$ B.Sc. College of Health Sciences, University of Buraimi \\ E-mail: gopi.v@uob.edu.om ${ }^{1}$
}

\begin{abstract}
Introduction: As per Oman government's health report (2013), Diabetes Mellitus (DM) prevalence in Omani population aged 18 and above was $12.3 \%$. Omani young adult and older population, are at a higher risk of being diabetic and developing diabetic retinopathy (DR). There are limited studies conducted in AlBatinah region, to evaluate the community's, DR related awareness and knowledge. Evidences on community's condition related knowledge can further help in enhancing the eye health care system.

Aim: To evaluate DR related awareness and knowledge, among Al Batinah population in Oman.

Material and Methods: This cross-sectional questionnaire-based study involved 100, randomly selected Omani participants. A self-designed validated questionnaire was used to assess awareness and knowledge of DR, amongst Al-Batinah population. The survey-based responses were analysed using Statistical Package for Social Sciences (SPSS) version 21.

Results: All participants have heard of DR. Relative or friend was the most common knowledge (51\%) source. $81 \%$ of the study participants were aware that DM leads to ocular complications. $94 \%$ participants believed that the eye care visit can be avoided, if DM is under control. Controlled diet was the highly agreed DR prevention strategy among the participants (88\%). Agreement on the use of medication, laser and surgery as a part of the treatment, was observed to be $29 \%, 62 \%$, and $70 \%$ respectively.

Conclusion: Awareness about DR, among the participants was high. However, the condition related knowledge variations were observed.
\end{abstract}

Keywords: Awareness and Knowledge-Diabetic Retinopathy, Diabetic Eye Disease.

\section{Introduction}

Universally, Diabetes Mellitus (DM) prevalence is expected to grow at around 592 million by the year 2035, from 382 million reported in 2013. Diabetic Retinopathy (DR) is one of the leading causes of vision impairment or loss, especially in the 20-74 age group. The condition shows systemic as well as ocular involvement. The systemic complications such as 'cardiovascular, neural and renal' involvements are commonly observed (Al Zarea, 2016). Cataract, Glaucoma, retinopathy and macular edema are the ocular complications secondary to DM (Nei.nih.gov, 2018).

DM prevalence in Oman is on rise (Khandekar et al., R., 2003). As per the governmental report, in 2013, DM prevalence in Omani population is $12.3 \%$ among the age group of 18 and above. Out of the total diabetic population, $10 \%$ of the population is affected by visual impairment associated with DR. The country maintains, a National DM Register and follows World Health Organization's recommended managerial guidelines. Health promotion and provision of the treatment for DM and DR are provided through primary health centers (Khandekar, 2015).

Noncompliance with the regular checkup to screen the associated disease complication and or treatment, could lead to further irreversible sight-threatening ocular conditions. This can further negatively affect the vision-related quality of life and also create an economic burden to the individual and his family. Establishing the vision rehabilitative services are also recommended by the health program auditors 
(Khandekar, 2015). Hence, to ensure the program success, it is important that the community is aware of the condition and its severity causing a socioeconomic impact. Knowledge related to regular screening, preventive measures, available treatment options and visual rehabilitative services for patients with the sight-threatening condition, is also important.

Many people with early-onset DR do not complain of any symptoms (M'Kiunga et al., K., 2017). Retinopathy in these cases keeps developing to a higher complicated level (Al Zarea, 2016). Edema due to the accumulation of fluid in the retina post leakage can result in a decreasing central vision (Shetgar et al., 2015). Retinal detachment can also be observed as severe complication of diabetic eye disease. Edema is usually painless and can have no or few symptoms at an early stage. The symptoms could be the primarily blurred vision but must be dealt promptly to prevent irreversible degenerative changes (Al Rasheed, 2017).The complication of DR is exacerbated in those who do not receive guidelines for medical care, DM prevention, attention to the symptoms and the probable personal neglect. The effect of DR on physical performance and role constraints ability to perform daily activities, work efficacy, participation in social life and recreational activities. Hence, it is recommended that all individuals affected with DM to undergo periodic ocular examinations and prevent future complications (Webeye.ophth.uiowa.edu, 2017).

With the higher prevalence and increased diagnostic efficacies of health care systems countrywide, DM has taken one of the leadership positions for causing a public health challenge (Shetgar et al., 2015). It has estimated total prevalence of $10 \%$, increasing up to $30 \%$ in the elderly population. El Haddad (1998), found the prevalence of DR in $42.4 \%$ of the referred patients. Further, the author also discovered that DR was more prevalent in Omani male population compared to females.

The increasing prevalence of DR is posing a significant eye health challenge (Khandekar et al., 2003). Unfortunately, the eye disease burden causes a tremendous effect on the individual's quality of life, if not treated at an early stage (Webeye.ophth.uiowa.edu, 2017). Many patients report to the eye health facilities at an advanced stage of DR (Al Rasheed et al., 2017). Level of accessibility, affordability, and awareness were the attributes for the nonattendance to eye health centers at an early stage (Khandekar et al., 2003). Out of these, lack of awareness is considered as the most important factor (Webeye.ophth.uiowa.edu, 2017).

In summary, DR can lead to irreversible vision loss. Omani old as well as young population, are at a higher risk of DM and DR. Early diagnosis and timely management of the condition play a pivotal role. Awareness regarding the condition within the affected or at-risk population is one of the critical factors for its detection and reduction of the overall disease burden. There are limited studies conducted in Al-Batinah region, to evaluate the community's, DR related awareness and knowledge. Understanding this disease related educational level, could be crucial to design further health promotional activities and or to form the future eye health policies.

\section{Materials and methods}

\section{Materials}

A self-designed and validated questionnaire was used to evaluate the awareness and knowledge among the involved participants. The survey was prepared in English and further translated into Arabic. The translation was validated by Arabic language expert.

\section{Questionnaire design}

A questionnaire was designed through a thorough literature review. The first part of the survey obtained the demographic details of the participants as well as patient's current diabetic status. The second part of the questionnaire consists of questions collecting patient categorical or open-ended responses. The questions were focused on understanding the patient's awareness and knowledge about ocular effects of DM, the importance of eye examination, treatment and rehabilitative options available for the management of DR. Participant's awareness about DR is self-declared. The questionnaire was validated by the subject experts. Field investigator was trained to conduct the survey. Participant's responses were obtained through the questionnaire and were compared with the model answers. 


\section{Setting and design}

It was a cross-sectional, questionnaire-based, prospective study. The study proposal obtained the necessary permissions from the Research and Ethics Committee, College of Health Sciences, University of Buraimi. The study included participants with different age, gender, occupation, socioeconomic background and participants with and without DM or DR. Prior consent was obtained from all the interested participants eligible for the study.

\section{Participants}

The study involved 100 participants residing in Al Batinah Governorate aged 16 years and above. The study was conducted from September 2017 until December 2017. The participants were selected randomly from the concerned population, having different age group and socioeconomic profile.

\section{Methods}

This study included 100 randomly selected native, Al Batinah residents. Participants with different age, gender, occupation, socioeconomic background and with or without DM or DR, were included in the study. Non-willing participants, age less than 16 years, participants involved with eye care services and individuals residing outside Al-Batinah region were excluded. The self-designed questionnaire collected responses from participants on the same day.

\section{Data analysis}

Participant's responses were obtained using hard copies. The data was also stored in soft copy using Microsoft Excel 2013. Statistical Package for Social Sciences (SPSS) version 21 was used to perform the descriptive analysis.

\section{Results}

\section{Demographic profile of the involved participants}

Table 1 represents the demographic profile of the involved participants. Out of 100 samples, 33 were males and 67 were females. Most of the participants were between the age group of $16-35$ years and were graduates. Only 17 participants were related to medical field by education and or occupation. All participants were native and were residing in Al-Batinah region of Oman

Table 1. Demographic profile of the participants

\begin{tabular}{|l|l|l|}
\hline Participants profile & Categories & Numbers/Percentage \\
\hline Age in years & $16-25$ & 31.0 \\
\hline & $26-35$ & 36.0 \\
\hline & $36-45$ & 4.0 \\
\hline & $46-55$ & 16.0 \\
\hline & $56-65$ & 13.0 \\
\hline Gender & Female & 67.0 \\
\hline & Male \\
\hline \multicolumn{3}{|l}{} \\
\hline Education & Graduate & 33.0 \\
\hline & Secondary & 34.0 \\
\hline & Illiterate \\
\hline Education related to Medical field \\
\hline & Medical \\
\hline
\end{tabular}


DOI: $10.21522 / \mathrm{TIJPH} .2013 .06 .02 . A r t 004$

ISSN: $2520-3134$

\begin{tabular}{|l|l|l|}
\hline \multicolumn{2}{|l|}{ Occupation status } & 83.0 \\
\hline & Employed & 36.0 \\
\hline & Unemployed & 44.0 \\
\hline & Student & 20.0 \\
\hline Occupation-related to medical field \\
\hline & Medical related & 17.0 \\
\hline & $\begin{array}{l}\text { Non-medical } \\
\text { related }\end{array}$ & 83.0 \\
\hline
\end{tabular}

\section{Participants diabetic profile and the source of information}

Awareness related to DR considered in the study is the self-declared. All participants have heard of DR. Relative or friend was the major information source for $51 \%$ of participants, followed by $22 \%$ who received information on DR from eye care professionals. Newspapers, were the least observed source of information (9\%). $16 \%$ and $1 \%$ of total participants had type 2 and type 1, DM respectively. The duration of diabetic in these participants ranged from 5 to 17 years. $93 \%$ had a family history of DM.

Table 2. Participant's diabetic profile and DR related source of information

\begin{tabular}{|c|c|c|}
\hline Profile & Category & Number/Percentage \\
\hline \multicolumn{3}{|c|}{ Heard of DR } \\
\hline & Yes & 100.0 \\
\hline \multicolumn{3}{|c|}{ If yes, the source of information } \\
\hline & Internet & 18.0 \\
\hline & Newspaper & 9.0 \\
\hline & Relatives & 51.0 \\
\hline & $\begin{array}{l}\text { Eye care } \\
\text { professional }\end{array}$ & 22.0 \\
\hline \multicolumn{3}{|c|}{ Do you have DM } \\
\hline & No & 83.0 \\
\hline & Yes & 17.0 \\
\hline \multicolumn{3}{|c|}{ Type of DM } \\
\hline & Type 1 & 1.0 \\
\hline & Type 2 & 16.0 \\
\hline \multicolumn{3}{|c|}{ Duration of DM in years } \\
\hline & 10 & 1.0 \\
\hline & 11 & 1.0 \\
\hline & 15 & 1.0 \\
\hline & 16 & 6.0 \\
\hline & 17 & 1.0 \\
\hline & 5 & 3.0 \\
\hline & 6 & 1.0 \\
\hline & 7 & 3.0 \\
\hline & Not applicable & 83.0 \\
\hline \multicolumn{3}{|c|}{ Family history of DM } \\
\hline & I don't know & 3.0 \\
\hline & No & 4.0 \\
\hline & Yes & 93.0 \\
\hline
\end{tabular}




\section{DM and eye health-knowledge related questions}

$81 \%$ of all the participants knew that DM could affect eyes and $49 \%$ stated that the vision can be affected. All involved participants did not know the ocular effects of DM apart from vision. Only $13 \%$ participants knew that both types of DM can affect vision. A high percentage (94\%) of participants knew that even controlled DM could affect the eye. The analysis showed that $59 \%$ of participants were aware that when the vision is affected, it would be hardly regained. A group representing $35 \%$ agreed for the level of ocular complications due to the condition as associated with the duration of DM (Refer to the Table 3 ).

Table 3. DM and eye health-knowledge related questions

\begin{tabular}{|c|c|c|}
\hline $\begin{array}{l}\text { DM and eye health- } \\
\text { Knowledge related questions }\end{array}$ & Categories & Number/Percent \\
\hline \multicolumn{3}{|l|}{ Does DM affect eye? } \\
\hline & I don't know & 19.0 \\
\hline & Yes & 81.0 \\
\hline \multicolumn{3}{|l|}{ Does DM affect vision? } \\
\hline & I don’t know & 26.0 \\
\hline & No & 25.0 \\
\hline & Yes & 49.0 \\
\hline \multicolumn{3}{|c|}{ What are the ocular effects of DM? } \\
\hline & I don't know & 51.0 \\
\hline & vision & 49.0 \\
\hline \multicolumn{3}{|c|}{ Which type of DM can affect the eye? } \\
\hline & Both & 13.0 \\
\hline & I don't know & 87.0 \\
\hline \multicolumn{3}{|c|}{ Can controlled DM, still affect eyes? } \\
\hline & I don't know & 6.0 \\
\hline & yes & 94.0 \\
\hline \multicolumn{3}{|c|}{ Can we regain vision completely, lost due to DM } \\
\hline & I don't know & 37.0 \\
\hline & No & 59.0 \\
\hline & Yes & 4.0 \\
\hline \multicolumn{3}{|c|}{ Is the duration of DM related to the level ocular complications? } \\
\hline & I don't know & 43.0 \\
\hline & No & 22.0 \\
\hline & Yes & 35.0 \\
\hline
\end{tabular}


DOI: $10.21522 / \mathrm{TIJPH} .2013 .06 .02 . A r t 004$

ISSN: $2520-3134$

\section{Prevention, treatment and other management related knowledge about DR}

Only 59\% felt the importance of ocular examination once an individual is affected by DM and out of them, $66.10 \%$ mentioned that they should visit the eye care practitioner only when the vision is affected. This contributes to $39 \%$ of the total study population. A high percentage of (94\%) participants believe that the eye care visit can be avoided if DM is under control.

Majority of the participants (88\%) agreed that the DR can be prevented with a managed diet. Agreement on the use of medication, laser and surgery as a part of the treatment, was observed to be $29 \%, 62 \%$, and $70 \%$ respectively. Only $14 \%$ population knew that visual rehabilitation can be used as a managerial option for the irreversible visual impairment occurred due to the condition. However, all of them did not know the type of available visual rehabilitation modes.

Table 4. Prevention, treatment and other management related knowledge about DR

\begin{tabular}{|c|c|c|}
\hline & Category & Percentage \\
\hline \multicolumn{3}{|c|}{ Knowledge related to the need for ocular examination } \\
\hline \multicolumn{3}{|c|}{ Is it important for a patient with DR to have an eye check-up? } \\
\hline & $\begin{array}{l}\text { I don't } \\
\text { know }\end{array}$ & 25.0 \\
\hline & No & 16.0 \\
\hline & Yes & 59.0 \\
\hline \multicolumn{3}{|c|}{ If yes, what should be the frequency of eye check-up? } \\
\hline & Annually & 20.0 \\
\hline & \begin{tabular}{|l|} 
Once vision \\
is affected
\end{tabular} & 39.0 \\
\hline \multicolumn{3}{|c|}{ Can we avoid eye examination if the DM is always under control? } \\
\hline & \begin{tabular}{|l|} 
I don't \\
know
\end{tabular} & 6.0 \\
\hline & Yes & 94.0 \\
\hline \multicolumn{3}{|c|}{ Knowledge related to the prevention/treatment of DR } \\
\hline \multicolumn{3}{|c|}{ Can a controlled diet help in preventing DR? } \\
\hline & $\begin{array}{l}\text { I don't } \\
\text { know }\end{array}$ & 12.0 \\
\hline & Yes & 88.0 \\
\hline \multicolumn{3}{|c|}{ Can medication help for treatment of DR? } \\
\hline & $\begin{array}{l}\text { I don't } \\
\text { know }\end{array}$ & 64.0 \\
\hline & No & 7.0 \\
\hline & Yes & 29.0 \\
\hline \multicolumn{3}{|l|}{ Can lasers help for treatment of DR? } \\
\hline & $\begin{array}{l}\text { I don't } \\
\text { know }\end{array}$ & 37.0 \\
\hline & No & 1.0 \\
\hline & Yes & 62.0 \\
\hline \multicolumn{3}{|c|}{ Can ocular surgery help for the treatment of DR? } \\
\hline & \begin{tabular}{|l|} 
I don't \\
know \\
\end{tabular} & 30.0 \\
\hline & Yes & 70.0 \\
\hline
\end{tabular}




\begin{tabular}{|c|c|c|}
\hline \multicolumn{3}{|c|}{$\begin{array}{l}\text { Are there visual rehabilitation modes of management for the } \\
\text { condition? }\end{array}$} \\
\hline & $\begin{array}{l}\text { I don’t } \\
\text { know }\end{array}$ & 64.0 \\
\hline & No & 22.0 \\
\hline & Yes & 14.0 \\
\hline \multicolumn{3}{|c|}{ If yes, please mention which rehabilitation mode you know? } \\
\hline & $\begin{array}{l}\text { Provided } \\
\text { wrong } \\
\text { responses }\end{array}$ & 14.0 \\
\hline
\end{tabular}

\section{Discussion}

This study aimed to evaluate awareness and knowledge of DR among Al-Batinah population, Oman. The awareness regarding DR was self-declared. Majority of this study participants were females, contributing to $67 \%$, and men were 33\%. A study done by Al Zarea (2016), in Saudi Arabia, had a higher percentage of men $(57.17 \%)$ compared to females. This study has a higher population of young adults in contrast to the study done by Al Zarea (2016) which had the majority of the older population. Awareness and knowledge about DR could differ in different age or gender. This could be due to the higher experience or higher percentage of exposure to the disease in the older population. Also, the gender-wise difference could be observed in different regions probability due to contextual differences in availing health care facilities.

\section{Awareness and knowledge of DR}

The DR awareness in this study is defined as participants, having heard of DR. All the study population has heard of DR. This is higher than the other studies done by Martha et. Al. (2011), Anupama et. al. (2015), Alasiri and Bafaraj (2016), Rani et al. (2008) and Thapa R et al. (2012) which had awareness percentages of $83 \%, 45.3 \%, 61 \%, 37.04 \%$ and $37 \%$ respectively. Interestingly, in the study by Alasiri and Bafaraj (2016), Type 1 diabetic patients had a significantly higher awareness than Type 2 . This is dissimilar to our findings which could be due to the smaller sample size of Type 1 diabetic participant in our study. The demographic awareness variation also exists which can be observed with lower awareness percentage (37\%) in a study done in Nepal (Thapa, 2012). In our study, participants were from different age groups, gender and with the different diabetic profile. Still, the higher awareness level reflects that in the study awareness is independent of the socioeconomic or diabetic health profile of the candidates.

\section{Knowledge related to DR}

Variations in knowledge regarding prevention, treatment and other managerial options of DR are observed in the study. For instance, controlling diet as a preventive measure of DR was found to be $88 \%$, whereas only $6 \%$ knew the importance of ocular examination even with the controlled status of DM. The knowledge variability could be multifactorial and can be explored separately. Khandekar et al. (2010), observed that the age, region and duration of DM as responsible factors for the knowledge level.

\section{Source of information}

In this study, relatives and friends were the most common knowledge source (51\%), whereas in a study done in Nepal by Thapa et al. (2012), stated physicians as the most common source with a similar percentage. Even lowest availed informative source in the later study was the radio. None of this study participant acquired information through the radio and very few receiving the information through newspapers (9\%). An appropriate platform needs to be identified while distributing DR related health information. 
DOI: $10.21522 / \mathrm{TIJPH} .2013 .06 .02 . A r t 004$

ISSN: $2520-3134$

\section{Knowledge related ocular effects of DM}

In this study, the knowledge regarding ocular complications resulting from DM was $81 \%$ which was slightly higher than that of the study in Saudi Arabia (75.62\%) (Al Zarea, 2016), India (70.2\%) (Shetgar et al., 2015) and slightly lesser than observed in a study done in Kenya (83\%) (M' Kiunga et al., 2017). A study done by Kiran and Mendonca (2016) found that $37.4 \%$ of their study participants have heard of ocular complications of DM and only $29.5 \%$ knew that vision can be affected due to DM. Hence, a higher percentage of our participants were aware of ocular and visual complications due to DR compared to other studies.

In our study, even though, the percentage of the population knowing the risk of ocular complication in DM is high, none of the participants knew the type of associated complications and only $49 \%$ knew that the vision will be impaired. Moreover, only $35 \%$ population knew the relation between DM duration and the severity of ocular complications. This knowledge level is very low compared to a study done by Khandekar et al. (2010), in Oman, which was 72.9\%. This could also be due to the close-ended question approach used in the later study. Moreover, Kiran and Mendonca (2016), found that $29.5 \%$ of the study involving population, knew that increased blood sugar level can affect vision. In contrast, Prabhu et. al. (2015), observed higher awareness prevalence in diabetic population regarding ocular $(72.50 \%)$ and visual complications (51\%) compared to our study population. This emphasizes the need for further knowledge building exercises within the non-diabetic community.

\section{Knowledge related to the preventive, treatment and other managerial methods}

$59 \%$ felt the importance of ocular examination, once an individual is affected by DM and out of them, $66.10 \%$ stated that they should visit the eye care practitioner only when the vision is affected. This percentage contributes to $39 \%$ of the total study population. The felt need of ocular examination is lesser in our study compared to the study done in Saudi Arabia (68.79\%) (Al Zarea, 2016).

Alarmingly, we found that $94 \%$ of our study participants believe that the eye care visit can be avoided if DM is under control. Anupama et al. (2015) found that $25.3 \%$ of their study participants knew the risk factors of DR.

Majority of the participants (88\%) agreed that the DR can be prevented with a managed diet. Agreement on the use of medication, laser and surgery as a part of the treatment, was observed to be $29 \%, 62 \%$, and $70 \%$ respectively. Only $14 \%$ population knew that visual rehabilitation can be used as a managerial option for the irreversible visual impairment occurred due to the condition. However, all the study participants did not know the type of available visual rehabilitation modes.

In summary, the study has found higher awareness about DR, but the variation in, the knowledge about the condition, preventive, treatment and managerial modes is observed. Community awareness and knowledge regarding this condition are crucial to support and ensure the success of the national level diabetic program and to reduce the burden of DR. Educating the population about the importance of early diagnosis, need for regular follow-ups and available prevention and treatments plan related to DR can be important.

\section{Future directions}

Further studies can be repeated with the higher sample size and in different parts of Oman. Though this study has focused only on the evaluation of awareness and knowledge of the involved participants, it is also important to identify community attitude and practices towards the condition. Moreover, there is a need to evaluate the knowledge, attitude, and practices of the medical professionals and especially primary eye care professionals (Raghad \& Fadwa, 2017) regarding the condition. As effective DR, related health promotion or education is vital, community perception towards the availed material can be important to assess. This could help in designing future educational resources, activities or performing necessary modifications. 


\section{Conclusion}

There is higher awareness about DR among the study population. However, DR related knowledge variability was observed with respect to its ocular effects, prevention, treatment and other managerial modes. Hence, there is potential for conducting DR related health education and health promotional programs. Similar studies involving higher sample size, rural population, primary health care professionals and in different governorates can be useful.

\section{Acknowledgements}

We cannot/ express enough thanks to our College of Health Sciences faculty, academic and administrative staff from different departments of University of Buraimi for their continued support and encouragement during the study.

We would also like to acknowledge our study participants for their precious time and efforts spent for the study.

\section{References}

[1]. Alasiri, R. A., \& Bafaraj, A. G. (2016). Awareness of Diabetic Retinopathy among Diabetic Patients in King Abdulaziz University Hospital, Jeddah, Saudi Arabia.

[2]. Al Rasheed, R., \& Al Adel, F. (2017). Diabetic retinopathy: Knowledge, awareness and practices of physicians in primary-care centers in Riyadh, Saudi Arabia. Saudi Journal of Ophthalmology, 31(1), 2-6.

[3]. Al Zarea, B. (2016). Knowledge, Attitude and Practice of Diabetic Retinopathy amongst the Diabetic Patients of of AlJouf and Hail Province of Saudi Arabia. JOURNAL OF CLINICAL AND DIAGNOSTIC RESEARCH. http://dx.doi.org/10.7860/jcdr/2016/19568.7862.

[4]. Diabetic Retinopathy for Medical Students. EyeRounds.org - Ophthalmology. Available at: http://webeye.ophth.uiowa.edu/eyeforum/tutorials/Diabetic-Retinopathy-Med-Students/index.htm. Accessed October 14, 2017.

[5]. El Haddad, O. A., \& Saad, M. K. (1998). Prevalence and risk factors for diabetic retinopathy among Omani diabetics. British journal of ophthalmology, 82(8), 901-906.

[6]. Khandekar, R. B., \& Al-Lawati, J. A. (2015). Epidemiology of diabetic retinopathy in Oman: Two decades of research. Oman journal of ophthalmology, 8(1), 1.

[7]. Khandekar, R., Al Harby, S., Al Harthy, H., \& Al Lawatti, J. (2010). Knowledge, attitude and practice regarding eye complications and care among Omani persons with diabetes-A cross sectional study. Oman journal of ophthalmology, 3(2), 60.

[8]. Khandekar, R., Al Lawatii, J., Mohammed, A. J., \& Al Raisi, A. (2003). Diabetic retinopathy in Oman: a hospital based study. British journal of ophthalmology, 87(9), 1061-1064.

[9]. M'Kiunga, K., Thuo, K., Margaret, C. and Miriam, W. (2017). Long-Term Complications and their Associated Risk Factors among Diabetic Patients at the Kenyatta National Hospital, Kenya. The International Annals of Medicine, 1(9).

[10]. Nei.nih.gov. (2018). Facts about Diabetic Eye Disease | National Eye Institute. Nei.nih.gov. Retrieved 10 February 2018, from https://nei.nih.gov/health/diabetic/retinopathy

[11]. Prabhu, M., Kakhandaki, A., \& Chandra, K. R. (2015). A hospital based study on awareness of diabetic retinopathy in diabetic individuals based on knowledge, attitude and practices in a tier-2 city in South India. Indian Journal of Clinical and Experimental Ophthalmology, 1(3), 159-163.

[12]. Shetgar, A. C., Patil, B., Salagar, M. C., \& Nanditha, A. (2015). Assessment of awareness of diabetic retinopathy among diabetics: A Clinical Survey. Indian Journal of Clinical and Experimental Ophthalmology, 1(4), 260-263.

[13]. Srinivasan, S., Raman, R., Kulothungan, V., Swaminathan, G., \& Sharma, T. (2017). Influence of serum lipids on the incidence and progression of diabetic retinopathy and macular oedema: Sankara Nethralaya Diabetic Retinopathy Epidemiology and Molecular Genetics Study (SN-DREAMS II). Clinical \& experimental ophthalmology. 
DOI: $10.21522 / \mathrm{TIJPH} .2013 .06 .02 . A r t 004$

ISSN: $2520-3134$

[14]. Thapa, R., Paudyal, G., Maharjan, N., \& Bernstein, P. S. (2012). Demographics and awareness of diabetic retinopathy among diabetic patients attending the vitreo-retinal service at a tertiary eye care center in Nepal. Nepalese Journal of Ophthalmology, 4(1), 10-16. 